\title{
Terrorism and the behavior of oil production and prices in OPEC
}

\author{
Manuel Monge \\ Universidad Francisco de Vitoria (UFV), Spain \\ Enrique Cristóbal \\ University of Navarra, Spain
}

\begin{abstract}
This paper contributes to the discussion of the role that terrorism plays in oil production and oil prices literature by studying the dynamics of terrorist attacks and oil production in OPEC. To this purpose, we use techniques based on fractional integration, fractional cointegration VAR (FCVAR) and wavelet analysis. Monthly data related to OPEC oil production, OPEC basket crude oil prices and terrorist attacks from January 1970 to December 2018 are used. The results, using fractional integration and cointegration techniques, indicate that the time series analyzed are highly persistent and there are no long-term deviations. Finally, using wavelet analysis, we conclude that the impact of the terrorist attacks in oil production and oil prices are non-significant and has a short-term component, recovering the original trend values between 1 and 10 months after the terrorist shock.
\end{abstract}

Keywords: Oil production; oil prices; terrorist attacks; fractional integration; FCVAR model; wavelet analysis.

JEL Classification: C00; C22; N4; E0.

Corresponding author:

Dr. Manuel Monge

Universidad Francisco de Vitoria

Faculty of Law and Business

E-28223 Madrid

Spain

Email: manuel.monge@ufv.es

Dr. Manuel Monge also acknowledges financial support from an internal Project of the Universidad Francisco de Vitoria. 


\section{Introduction}

According to Aon (2020) in 2016 the world suffered a $14.2 \%$ increase in the number of terrorist attacks. In recent decades, terrorism has represented a significant and growing threat to society, as it affects not only the life or integrity of people, but also has a direct impact on economies (Orbaneja et al., 2018). To take one of the most noteworthy examples in the literature, it is estimated that the short-term economic cost of the terrorist attacks of September 11 in New York cost approximately \$21.4 billion dollars (Richman et al., 2011).

From the beginning of the industrial revolution, and despite the progress in the implementation of clean energy during the last years, oil continues to be the most widely used energy source globally (IEA, 2019). It plays a fundamental role in political and economic stability, being also a potential cause of wars and civil conflicts (Collier and Hoeffler, 1998; Ross, 2004 a,b; Fearon, 2005; Humphreys, 2005; Colgan, 2013). This is mainly due to the fact that most developed economies are heavily dependent on oil and of course it is a limited natural resource. This situation makes these countries extremely vulnerable to external production and price volatilities, especially those coming from the main market players: OPEC, U.S. and Russia (Bahgat, 2004). In this sense, and given that oil has a strategic value for many powerful countries that are dependent on it, it is very common for terrorists to target oil facilities (pipelines, tankers, refineries, oil fields, chokepoints, etc.) in oil-producing countries with the aim of economically disrupting foreign energy supplies (Adams, 2003; Luft and Korin, 2004). Therefore, there exists a deep interest in knowing what role terrorism plays in oil production and oil prices behavior.

As we mention before, terrorism seems a priori one of the main candidates likely to 
affect oil prices and production, since the production infrastructures in producing countries can be damaged or influenced by terrorist activities, either by appropriation or by destruction. Specifically, in 2016, terrorist attacks on oil and gas infrastructure comprised almost $42 \%$ of all terrorist attacks on commercial interests (Aon, 2020). In addition, authors such as Tichy (2019) claim that attacks on the energy sector form a very relevant part of the military strategy of such notorious terrorist organizations as the Islamic State (IS), since oil is an important source of financing for them.

In addition, the producing countries are in many cases very poorly diversified economies and unable to cope with certain turbulences or conflicts, which greatly reduces the productive capacity of the oil industry, affecting production and prices (Ross 2001; Jensen and Wantchekon 2004; Morrison 2009; Aslaksen 2010 and Ramsay 2011). Phan et al. (2021) affirm that terrorism events that take place in oil producing countries have a greater effect on oil prices. The U.S. Energy Information Administration (EIA 2019) affirms that, of today's current top twenty oil producing countries, seven are located in the Middle East and the North Africa region, putting this area at potential risk to terrorism damages. Moreover, Şen and Babalı (2007) indicated that it is important to note that OPEC members such as Saudi Arabia, Iran, Iraq, Kuwait, UAE or Qatar comprise $65 \%-70 \%$ of the world's oil reserves.

OPEC seeks to actively manage oil production in its member countries by setting production targets. This organization is responsible for about $40 \%$ of the world's crude oil production and, historically, crude oil prices have seen increases at times when OPEC's production targets are reduced, thereby affecting world economies. Coleman (2012) concluded that prices reflect supply-demand equilibrium and that shocks are caused by exogenous shortfalls in supply, the initiators of which lie in the behavior of markets, 
inventories and suppliers or when demand rises faster than expected.

Moreover, there is historical evidence that terrorist attacks in OPEC countries have affected their production capacity, and consequently the supply of crude. For example, a pipeline attacked in February 2016 in Nigeria paralyzed oil production, with production losses of around 250,000 barrels. Along these lines, Al-Quaeda also attacked a gas field in Algeria in 2016, causing significant curbs on its production. ISIS also attacked major oil distribution ports in Libya in 2016. In February 2016, a pipeline was attacked in Kurdistan, reducing oil production by 600,000 barrels per day (Bassil et al., 2018).

The goal of this paper is to understand the behavior of OPEC oil prices and OPEC oil production under the assumption of terrorist attacks in these countries. To this purpose, we analyze the statistical properties of these time series, measuring the degree of persistence by using fractional integration techniques (see Monge et al. 2017a, b; Monge and Gil-Alana, 2020; Monge and Gil-Alana, 2021, among others). Moreover, we analyze the long-term relationship of the time series using the Fractional Cointegration VAR (FCVAR) approach (see Johansen and Nielsen, 2010, 2012). Finally, we examine the possible structural changes in oil prices and oil production caused by the terrorist attacks in OPEC countries using methodologies based on Bai and Perron (2003) and wavelet transform (see Aguiar-Conraria and Soares, 2014).

To the best of our knowledge, this is the first paper that analyzes the statistical properties of terrorist attacks and crude oil production and prices in OPEC using the methodologies mentioned above. Therefore, the key objective of our study is to examine whether the impact of terrorism on the OPEC oil prices and OPEC oil production is temporary or permanent. This knowledge is extremely relevant to analyze what the effects of terrorist attacks may be for oil production and oil prices in OPEC. The study is both 
crucial and timely as, despite the importance of oil in the literature in economics, political science and international relations, there is surprisingly little scholarly discussion regarding the role terrorism plays in oil production in OPEC.

The rest of the paper is organized as follows. Section 2 reviews the literature about terrorist attacks and oil production. Section 3 provides a brief introduction to the mathematics of wavelets and explains how the metric is derived that is used to compare terrorist attacks and OPEC's crude oil production. The data are described in Section 4 and the main results are also presented in that section, while Section 5 concludes.

\section{Literature review}

There are numerous authors who have studied the different factors that affect the evolution of oil production and oil prices. These factors include oil demand and supply (Baumeister and Kilian, 2014; Cooper, 2003; Hamilton, 2009; Baumeister and Peersman, 2013; Huang et. al, 2017), oil inventory (Baumeister and Kilian, 2012), interest rates (Arora and Tanner, 2013), convenience yield (Murat and Tokat, 2009), news (Narayan, 2020), oil shocks (Hamilton, 2009), oil futures (Jun, 2017), exchange rates (Beckmann and Czudaj, 2013) and equity markets (Zhang and Wei, 2011). Lee et al. (2017) analyze how country risk affects fluctuations in the price of oil, concluding that exporting countries are positively affected by these shocks. Lambrechts and Blomquist (2017) have also deeply reflected on the importance of political-security risk in the oil and gas industry. Narayan (2020) answer the question: can stale oil price news predict stock returns? Using time-series predictive regression models estimated for 45 countries, they show that oil price news turns out to be more powerful in predicting returns in a horserace with oil price. More recently, authors such as Gil-Alana and Monge (2020), Kingsly, K. and Henri, K. (2020) and Salisu et al. (2020) have studied the effect of the 
COVID-19 crisis on crude oil prices. Along the same lines, other authors such as Bakas and Triantafyllou (2020) argue that in times of higher uncertainty caused by pandemics, supply and demand fall rapidly and steadily over time due to the increase in the price elasticity.

The presence of terrorist events, wars and military conflicts also seem to have an important effect on the fluctuations associated with oil production and prices (Hendrix, 2017). In recent decades, terrorism has increased its influence on the oil industry, decisively affecting the behavior of production and prices (Adams, 2003; Luft and Korin, 2004). For instance, events such as the Suez Canal crisis 1956-1957, the OPEC oil embargo of 19731974, the Iranian Revolution of 1978-1979, the Iran and Iraq war of 1980, the first Persian Gulf War in 1990-1991 are conflicts that for authors such as Bagchi (2017) are unequivocally associated with an increase in the price of oil.

Despite the enormous importance of the OPEC countries in global oil production and reserves, coupled with the fact that it is precisely in these countries where there is a greater presence of attacks and terrorist groups, there are not many specific studies that analyze the behavior of oil production and prices for this group of countries. As far as we know, none of them use techniques based on fractional integration, fractional cointegration VAR (FCVAR) or wavelet analysis.

Hoffman (2006) argues that important and strategic sectors such as energy, and more specifically the producers of fossil fuels such as oil, have become targets for terrorism as in many cases they represent the main funding source for these terrorist groups. Şen and Babalı (2007) conclude in their study that terrorist attacks also have direct effects over oil supply security issues. On the other hand, Fattouh (2007) warns how high oil prices, threats of terrorist attacks, instability in many oil-exporting countries and the rise in so-called 'oil 
nationalism', have raised serious concerns about the security of oil supplies, which can lead to the supply in these countries being compromised thereby affecting prices. Cook (2008), carries out a descriptive study on the trajectory of terrorist attacks on oil targets perpetrated by radical groups.

Blomberg et al., (2009) found that terrorism has a positive impact on oil stock prices. Toft (2011) investigates how often and how many outbreaks of intra-state conflict in oil producing states translate into oil supply shortfalls. He concludes that outbreaks of conflict do not translate into production losses with any degree of certainty and, in fact, in many cases conflict was often followed by increasing oil production. Barros et al. (2011) use monthly data from 1973 to 2008 for thirteen OPEC members to study the time series behavior of oil production within a fractional integration modelling framework recognizing the potential for structural breaks and outliers. Contrary to most authors, Tahir Suleman (2012) affirms that information on terrorist attacks does not significantly affect operations in the oil industry. Kollias et al. (2013) argue that geopolitical events, especially war and terrorism, can have an important effect on oil market behavior. Moreover, they affirm that the time length of this effect and its intensity can vary and that terrorism is a one-off event that cannot be forecasted by the market.

Chen et al. (2016) quantitatively analyze the impacts of OPEC's political risk on Brent oil prices through Structural Vector Autoregression (SVAR) models. Monge et al. (2017a) investigate crude oil price behavior before and after military conflicts and geopolitical events since World War II using techniques based on unit roots and fractional integration, and finding evidence of persistence and breaks in the oil prices series and stationary long memory in the absolute returns. However, they do not observe significant differences before and after the conflicts and geopolitical events. In their study on Middle East and North Africa, Miao et al. (2017) show that in countries where oil prices rise, 
terrorist attacks have a clear effect on these rises. Orbaneja et al. (2018) studies the impact of terrorism on the oil market, focusing on the type of attack, distance, type of attack, size of the same; among others. Their results suggest that the various types of attacks lead to a large positive abnormal return of crude oil prices. Javid and Ahmad, (2020) study the impact of terrorist attacks and political events on returns and volatility in the oil and gas sector of the Karachi Stock Exchange from the period of 2004 to 2014. Their results indicate that the oil and gas sector reacts to terrorism and political events, although these effects become insignificant in the long run. By using a unique dataset that merges terrorism activity with oil prices, they collet daily data from West Texas Intermediate and GTD (Global Terrorism Database), Phan et al. (2021) carry out a study that proves that terrorist attacks, both through oil production and investment channels, can be a predictor of the behavior of oil prices. They affirm that terrorist attacks have a positive effect on oil prices, with those that occur in producing countries having the greatest effect.

\section{Methodology}

\subsection{Unit Roots}

The unit roots could be tested in many different ways. We use ADF tests based on Fuller (1976) and Dickey and Fuller (1979), assuming that these methodologies are effective when the data are stationary. There are many other tests available to calculate unit roots that have greater power such as Phillips (1987) and Phillips and Perron (1988) in which a non-parametric estimate of spectral density of $u_{t}$ at the zero frequency has been used. Also, considering the deterministic trend we use the methodology based on Kwiatkowski et al. (1992), Elliot et al. (1996) and Ng and Perron (2001) and produce the same results. In addition, we use two unit root tests with structural breaks in the time series. The methodology proposed by Narayan and Popp (2010) is an ADF-type unit root test that uses two different specifications for the deterministic component, allowing for two 
structural breaks in the level (Model 1) and two structural breaks in the level and in the slope of the deterministic trend component (Model 2). On the other hand, the LM test, proposed by Lee and Strazicich (2003) take into consideration two breaks in the intercept and two breaks in the intercept and trend (Model 1 and Model 2, respectively).

\subsection{ARFIMA (p, d, q) model}

An important characteristic of many economic and financial time series is their nonstationary nature, which can be described by a variety of models. Until the 1980s the standard approach was to use deterministic (linear or quadratic) functions of time, thus assuming that the residuals from the regression model were $\mathrm{I}(0)$ stationary. Later on, and especially after the seminal work of Nelson and Plosser (1982), a general consensus was reached that the non-stationary component of most series was stochastic, and unit roots (or first differences, I(1)) were most appropriate for them. However, the I(1) case is merely one particular model that can describe such behavior. In fact, the number of differences required to achieve $\mathrm{I}(0)$ stationarity is not necessarily an integer value but could be any point on the real line, including fractional values. In the latter case, the process is said to be fractionally integrated or $\mathrm{I}(\mathrm{d})$.

Long memory is a feature of observations that are far apart in time but highly correlated. This can be captured by fractionally integrated or I(d) models of the form:

$$
(1-L)^{d} x_{t}=u_{t}, \quad t=1,2, \ldots
$$

where $x_{t}$ refers to a time series, $d$ refers to any real value, $L$ refers to the lag-operator $\left(L x_{t}=x_{t-1}\right)$ and $u_{t}$ refers to $\mathrm{I}(0)$ which is the covariance stationary process where the spectral density function is positive and finite at the zero frequency, displaying in the weak form a type of time dependence. So, for example, if $u_{t}$ is ARMA (p, q), $x_{t}$ is then said to be ARFIMA (p, d, q). 
Although fractional integration can also occur at other frequencies away from zero, as in the case of seasonal and cyclical fractional models, the series used for our analysis do not have these features and hence we estimate standard I(d) models as in (1). The idea of fractional integration was introduced by Granger and Joyeux (1980), Granger (1980, 1981) and Hosking (1981), though Adenstedt (1974) had already showed awareness of its representation. The polynomial $(1-L)^{d}$ in equation (1) can be expressed in terms of its binomial expansion, such that, for all real $d, x_{t}$ depends not only on a finite number of past observations but on the whole of its past history. In this context, d plays a crucial role since it indicates the degree of dependence of the series: the higher the value of $d$ is, the higher the level of association between the observations will be.

Given the parameterization in (1) one can distinguish between several cases depending on the value of the parameter $d$, several specifications based on (1) can be observed. Thus, if $\mathrm{d}<0, \mathrm{x}_{\mathrm{t}}$ is said to be anti-persistent, with the series exhibiting zero spectral density at the origin (Dittmann and Granger, 2002) and switching signs more frequently than a random process. The process is short memory or $\mathrm{I}(0)$ when $d=0$ in (1). This occurs because $x_{t}=u_{t}$. Long memory process $(\mathrm{d}>0)$ is the name given when there is a high degree of association over a long time. With this last assumption, the process is still covariance stationary if $d<0.5$ because the infinite sum of the autocovariances is still finite. Our interpretation of this can also be related to the issue of mean reversion. If the series reverts to the mean, shocks will be transitory and this happens when $d$ is smaller than 1 . In contrast to the above, the shocks are expected to be permanent when $d \geq 1$. Although there are several procedures for estimating the degree of long-memory and fractional integration (Geweke and Porter-Hudak, 1983; Phillips, 1999, 2007; Sowell, 1992; Robinson, 1994, 1995a,b; etc.) we follow the Akaike information criterion (AIC) (Akaike, 1973) and the Bayesian information criterion (BIC) (Akaike, 1979) to select the 
most appropriate ARFIMA model and we follow Sowell (1992) and his likelihood process to present our results.

\subsection{Fractional Cointegration (FCVAR) model}

A method known as Fractionally Cointegrated Vector AutoRegressive (FCVAR) was introduced by Johansen (2008) to check for a multivariate fractional cointegration model. It was further expanded by Johansen and Nielsen (2010, 2012). It is one step ahead of the Cointegrated Vector AutoRegressive model (Johansen, 1996), which is named CVAR, and it allows for series integrated of order $d$ and that cointegrate with order $d-b$, with $b$ $>0$. To introduce the FCVAR model, we present first the non-fractional CVAR model.

Let $Y_{t}, t=1, \ldots, T$ be a $\mathrm{p}$-dimensional I(1) time series. The CVAR model is:

$$
\Delta Y_{t}=\alpha \beta^{\prime} Y_{t-1}+\sum_{i=1}^{k} \Gamma_{i} \Delta Y_{t-i}+\varepsilon_{t}=\alpha \beta^{\prime} L Y_{t}+\sum_{i=1}^{k} \Gamma_{i} \Delta L^{i} Y_{t}+\varepsilon_{t}
$$

$\Delta^{b}$ and $L_{b}=1-\Delta^{b}$, representing the difference and the lag operator, is used to derive the FCVAR model. We then obtain:

$$
\Delta^{b} Y_{t}=\alpha \beta^{\prime} L_{b} Y_{t}+\sum_{i=1}^{k} \Gamma_{i} \Delta L_{b}^{i} Y_{t}+\varepsilon_{t},
$$

which is applied to $Y_{t}=\Delta^{d-b} X_{t}$ such that

$$
\Delta^{d} X_{t}=\alpha \beta^{\prime} L_{b} \Delta^{d-b} X_{t}+\sum_{i=1}^{k} \Gamma_{i} \Delta^{b} L_{b}^{i} Y_{t}+\varepsilon_{t},
$$

Where, $\varepsilon_{t}$ is a term with mean zero, and variance-covariance matrix $\Omega$ is $\mathrm{p}$ dimensional independent and identically distributed. As in the CVAR model, the parameters can be interpreted as follows. $\alpha$ and $\beta$ are $p \times r$ matrices, where $0 \leq r \leq p$. The relationship in the long-run equilibria in terms of cointegration in the system is due to the matrix $\beta$. The parameter $\Gamma_{i}$ controls for the short-run behavior of the variables. Finally, the deviations from the equilibria and their speed in the adjustment is because of the parameter $\alpha$. Thus, the FCVAR model allows simultaneous modelling of the long-run equilibria, the adjustment responses to deviations from those and the short-run dynamics 
of the system. As an intermediate step towards the final model, we consider a version of model (2) with $d=b$ and a constant mean term for the cointegration relations. That is to say:

$$
\Delta^{d} X_{t}=\alpha\left(\beta^{\prime} L_{d} X_{t}+\rho^{\prime}\right)+\sum_{i=1}^{k} \Gamma_{i} \Delta^{d} L_{d}^{i} X_{t}+\varepsilon_{t}
$$

Johansen and Nielsen (2012) and Nielsen and Morin (2014) discuss estimation and inference of this model.

It is noteworthy that fractional differencing is defined in terms of an infinite series but any actual sample will include only a finite number of observations. In order to calculate the fractional differences one can assume that $X_{t}$ was zero before the start of the sample. The bias introduced by this assumption is analyzed by Johansen and Nielsen (2014) using higher-order expansions. They showed that it can be completely avoided by including a level parameter $\mu$ that shifts each of the series by a constant.

The estimated empirical model is the following:

$$
\Delta^{d}\left(X_{t}-\mu\right)=L_{d} \alpha \beta^{\prime}\left(X_{t}-\mu\right)+\sum_{i=1}^{k} \Gamma_{i} \Delta^{d} L_{d}{ }^{i} X_{t}+\varepsilon_{t}
$$

The asymptotic analysis in Johansen and Nielsen (2012) shows that the maximum likelihood estimators of $\left(d, \alpha, \Gamma, \ldots, \Gamma_{2}\right)$ are asymptotically normal, while the maximum likelihood estimator of $(\beta, \rho)$ is asymptotically mixed normal when $d_{0}<1 / 2$ and asymptotically normal when $d_{0}>1 / 2$. FCVAR models have recently been estimated in numerous empirical papers (Baruník and Dvořáková, 2015; Maciel, 2017; Aye et al., 2017; Dolatabadi et al., 2018; Jones, Nielsen and Popiel, 2014; Gil-Alana and Carcel, 2020; Poza and Monge, 2020; etc.).

Nielsen and Popiel (2018) provide Matlab computer programs for the calculation of estimators and test statistics.

\subsection{Wavelet Analysis}


Wavelet methodology is used to analyze time series in the time-frequency domain. Following Vacha and Barunik (2012), Aguiar-Conraria and Soares (2011, 2014), Dewandaru et al. (2016), Tiwari et al. (2016), Jammazi et al. (2017) and others that apply Continuous Wavelet Transform (CWT) in finance and economics research, two tools are used in this paper: wavelet coherency and wavelet phase-difference.

There are two reasons for using this methodology: first, stationarity is not a requirement to carry out a wavelet analysis and, second, it is interesting to study the interaction of both the time and the frequency domains of the time series themselves to find evidence of the potential changes in its pattern.

The wavelet coherency is a two-dimensional diagram that correlates time series and identifies hidden patterns or information in the domain of time and frequency. The $W T_{x}(a, \tau)$ of a time series $x(t)$, that is obtained by projecting a mother wavelet $\psi$, is defined as:

$$
W T_{x}(a, \tau)=\int_{-\infty}^{+\infty} x(t) \frac{1}{\sqrt{a}} \psi^{*}\left(\frac{t-\tau}{a}\right) d t
$$

where $W T_{x}(a, \tau)$ are the wavelet coefficients of $x(t)$; the position of a wavelet in the frequency domain is defined by $a$, and $\tau$ is the position in the time domain. Thus, the wavelet transform provides information concurrently on time and frequency by mapping the original series into a function of $\tau$ and $a$. A Morlet wavelet has been chosen as a mother wavelet to carry out our analysis since it is a complex sine wave within a Gaussian envelope, so we will be able to measure the synchronism between time series. (See Aguiar-Conraria and Soares 2014 for the properties of this wavelet and for a more complete understanding of this procedure).

To understand the interaction and the integration between the two series we use the wavelet coherence defined as: 


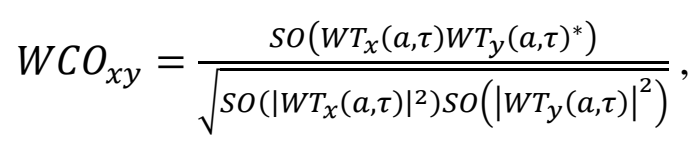

where $S O$ is a smoothing operator in both time and scale. Without the smoothing operator, the wavelet coherency would be always one for all times and scales (see Aguiar-Conraria et al. 2008 for details). Matlab computer programs for the calculation of estimators and test statistics in the CWT are provided in Aguiar-Conraria's website ${ }^{1}$.

\section{Data}

The data examined in this work correspond to OPEC crude oil production ${ }^{2}$ and OPEC basket oil price and the total number of terrorist events registered by month in each country over the period 1970:01-2018:12. The crude oil production and the crude oil prices dataset were obtained from Thomson Reuters Eikon database.

On the other hand, the total number of terrorist events by month was obtained from the Global Terrorism Database (National Consortium for the Study of Terrorism and Responses to Terrorism (START) 2020) ${ }^{3}$, which records both domestic and transnational terrorism ${ }^{4}$. This database is made up of more than 100 structured variables (each attack's location, tactics and weapons, targets, perpetrators, casualties and consequences, and general information) and unstructured variables (summary descriptions of the attacks and more detailed information on the weapons used, specific motives of the attackers, property damage, and ransom demands, among others). For this last dataset we have had to select this qualitative information for each of the OPEC member countries, convert each event or attack into a numerical value analyzed over time, and then

\footnotetext{
${ }^{1}$ https://sites.google.com/site/aguiarconraria/joanasoares-wavelets

${ }^{2}$ OPEC total crude oil production is measured in million barrels per day.

${ }^{3}$ Type of recorded events: assassination, hijacking, kidnapping, barricade incident, bombing/explosion, armed assault, unarmed assault, facility/infrastructure attack).

${ }^{4}$ Terrorism is transnational when an incident in the venue country concerns perpetrators or victims from another country.
} 
aggregate this data into a monthly time series in order to carry out our analysis with total oil production in OPEC countries. The number of zero values with daily and weekly data for the time series of terrorist attacks and the unavailability of daily or weekly data for the time series of oil production in OPEC countries has limited our ability to carry out the analysis at other time frequencies.

Figure 1 displays the time series plots of the number of terrorist attacks and the total crude oil production in OPEC countries. The grey part of the figure identifies some relevant events identified in Monge et. al (2017a) such as the Iranian Revolution of 1978/79, the Iran-Iraq War of 1980-1988, the Persian Gulf War of 1990/91, the Venezuelan crisis of 2002 and the Iraq War of 2003, and the Libyan uprising of 2011. Also, we have identified relevant terrorist attacks such as September 11, 2001.

As is shown in the figure, the trends of terrorist attacks and crude oil production at OPEC countries increase, leading us to think that terrorist attacks may have some influence on the crude oil production due to the arguments given by Lee (2016) (see for example the periods between the years 1995-1998, 2000-2003, among others).

Figure 1: Terrorist Attacks in OPEC Countries and OPEC Total Crude Oil Production 


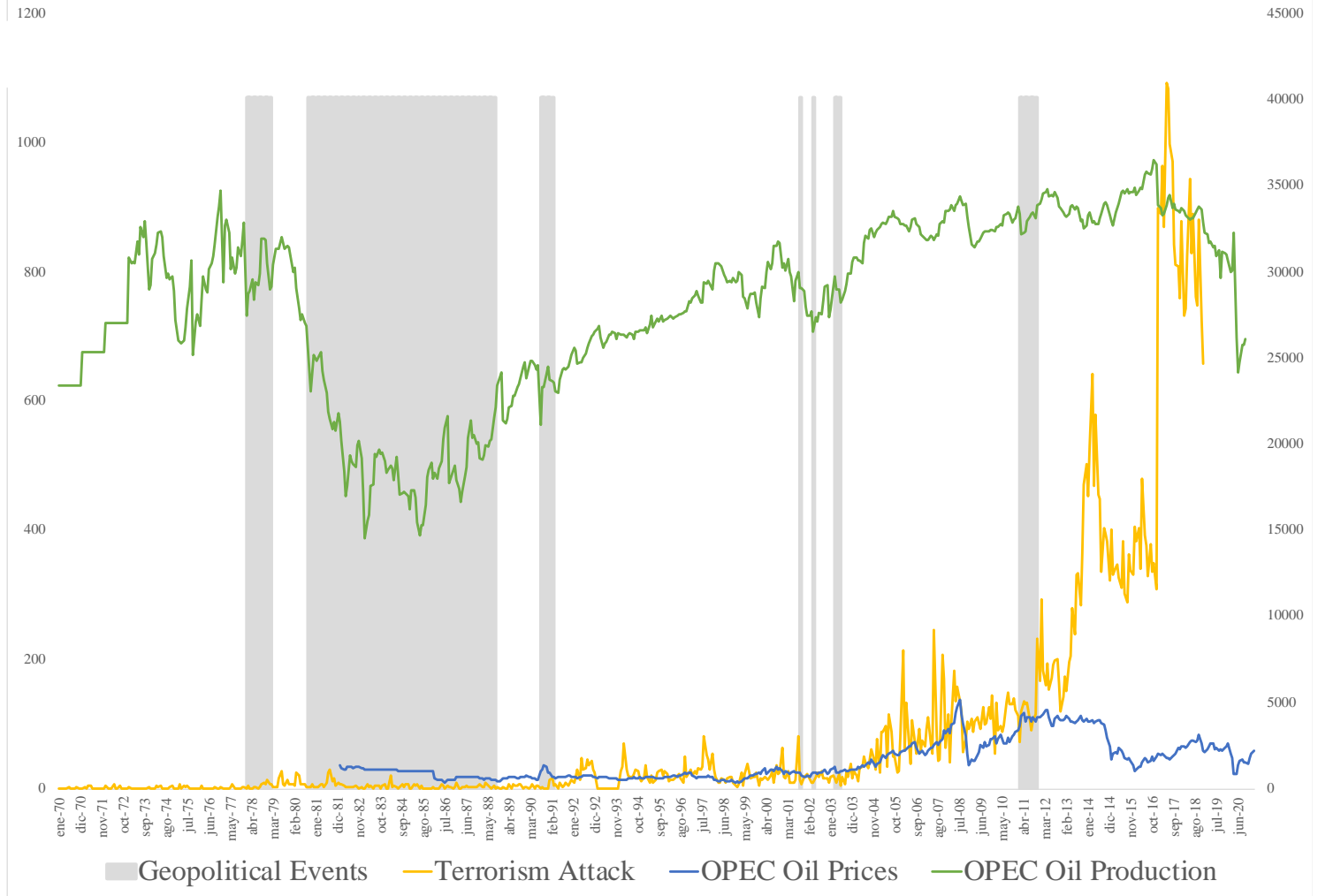

\section{Empirical results}

\subsection{Unit Roots}

We have calculated the three standard unit roots tests to analyze the statistical properties of the terrorist attacks, OPEC oil prices and OPEC oil production.

We have obtained the results using the Augmented Dickey-Fuller (ADF) test, the Phillips Perron (PP) test and the Kwiatkowski-Phillips-Schmidt-Shin (KPSS) test displayed in Table 1, which suggest that the selected time series are non-stationary I(1). Calculating the first differences we observe that the series become stationary $\mathrm{I}(0)$ (see Table 1).

Table 1. Unit root tests based on ADF, PP and KPSS

$\begin{array}{lll}\text { ADF } & \text { PP } & \text { KPSS }\end{array}$

(i)

(ii)

(iii)

(i)

(ii)

(iii)

(ii)

(iii) 


\begin{tabular}{lccccccccc}
\hline \hline OPEC oil prices & -0.9578 & -1.9084 & -2.7911 & -0.9399 & -1.8907 & -2.8405 & 1.7157 & 0.2759 \\
& & & & & & & & \\
d_OPEC oil prices & $-17.6672 *$ & $-17.6491^{*}$ & $-17.6276^{*}$ & $-17.5198^{*}$ & $-17.4992^{*}$ & $-17.4758^{*}$ & $0.0554^{*}$ & $0.0510^{*}$ \\
\hline \hline
\end{tabular}

Original Data and First Differences in OPEC oil production

\begin{tabular}{lcccccccc}
\hline \hline OPEC oil production & 0.1290 & -1.9179 & -2.3825 & 0.3544 & -1.6383 & -2.1358 & 1.5260 & 0.4075 \\
& & & & & & & & \\
d_OPEC oil production & $-25.8849^{*}$ & $-25.8738^{*}$ & $-25.8516^{*}$ & $-26.8155^{*}$ & $-26.8594^{*}$ & $-26.8328^{*}$ & $0.0766^{*}$ & $0.0757^{*}$
\end{tabular}

(i) Refers to the model with no deterministic components; (ii) with an intercept, and (iii) with a linear time trend.* Denotes a statistic significant at the 5\% level. For ADF and PP, the 5\% critical value is -1.9418 for no deterministic components; -2.8707 with an intercept; -3.4245 with a linear time trend. For KPSS, the 5\% critical value is 0.4630 with an intercept component; 0.1460 with a linear time trend.

Also, we apply two unit root tests with structural breaks onto our time series. The two unit root tests are Narayan and Popp (2010) and the Lee and Strazicich (2003) Lagrange Multiplier (LM) test. We have used these tests because, according to Narayan and Popp (2013) they provide better results in terms of power and size. Also, these methodologies allow for two structural breaks and neither accommodates heteroskedasticity which is particularly problematic with frequency higher than annual data.

The methodology proposed by Narayan and Popp (2010) is an ADF-type unit root test that uses two different specifications for the deterministic component, allowing for two structural breaks in the level (Model 1) and two structural breaks in the level and in the slope of the deterministic trend component (Model 2). On the other hand, the LM test take into consideration two breaks in the intercept and two breaks in the intercept and trend (Model 1 and Model 2, respectively).

These methodologies are important because most standard unit roots will bias towards non-rejection of the unit root

Table 2 presents the results of both methodologies. According to our results using most standard unit roots suggests that the selected time series are non-stationary I(1), but these 
more contemporary methods are important because they show that, taking into account two structural breaks, the time series analyzed in this research paper are stationary $\mathrm{I}(0)$ (see Table 2).

Table 2. Unit root tests based on Narayan and Popp (2010) and Lee and Strazicich (2003)

Narayan and Popp (2010)

\section{Break in intercept}

Break in intercept and trend

\begin{tabular}{|c|c|c|c|c|c|c|}
\hline Series & $\begin{array}{c}\text { Test } \\
\text { statistic }\end{array}$ & TB1 & TB2 & $\begin{array}{c}\text { Test } \\
\text { statistic }\end{array}$ & TB1 & TB2 \\
\hline $\begin{array}{l}\text { OPEC Oil } \\
\text { Prices }\end{array}$ & -5.826 & 2006:11 & 2014:05 & -7.072 & 2000:01 & 2014:07 \\
\hline $\begin{array}{l}\text { OPEC Oil } \\
\text { Production }\end{array}$ & -6.366 & 1979:12 & 1988:05 & -5.987 & 1979:12 & 2008:08 \\
\hline $\begin{array}{l}\text { Terrorism } \\
\text { attacks }\end{array}$ & -5.213 & 2012:12 & $2014: 10$ & -7.417 & 2012:07 & 2014:03 \\
\hline \multicolumn{7}{|c|}{ Lee and Strazicich (2003) } \\
\hline $\begin{array}{l}\text { OPEC Oil } \\
\text { Prices }\end{array}$ & -2.734 & 2008:11 & 2011:09 & -5.887 & $2004: 10$ & 2014:10 \\
\hline $\begin{array}{l}\text { OPEC Oil } \\
\text { Production }\end{array}$ & -2.554 & 1976:11 & 1982:12 & -4.768 & 1980:04 & 1987:07 \\
\hline $\begin{array}{l}\text { Terrorism } \\
\text { attacks }\end{array}$ & -3.495 & 2011:11 & 2014:11 & -6.937 & 2005:05 & 2012:12 \\
\hline \multicolumn{7}{|c|}{$\begin{array}{l}\text { For Narayan and Popp (2010) unit root test, the critical values for Model } M 1=-4.67,-4.08,-3.77 \text { at } \\
1 \%, 5 \%, 10 \% \text {, respectively. The critical values for Model } M 2-5.29,-4.69,-4.40 \text { at } 1 \%, 5 \%, 10 \%, \text { respectively. } \\
\text { TB1 and TB2 are the dates of the structural breaks. } \\
\text { For Lee and Strazicich (2003) unit root test, the critical values for Model } M 1=-3.55,-3.005,-2.732 \text { at } \\
1 \%, 5 \%, 10 \% \text {, respectively. The critical values for Model } M 2=-4.65,-4.14,-3.89 \text { at } 1 \%, 5 \%, 10 \%, \text { respectively. } \\
\text { TB1 and TB2 are the dates of the structural breaks. }\end{array}$} \\
\hline
\end{tabular}

\subsection{Fractional Integration}

Following the results obtained using unit root methods in the three time series and due to the low power of the unit root methods under fractional alternatives ${ }^{5}$, we also employed fractional methods, and used ARFIMA (p, d, q) models to study the persistence of the OPEC oil prices and OPEC oil production time series. The Akaike information criterion

\footnotetext{
${ }^{5}$ See Diebold and Rudebusch (1991), Hassler and Wolters (1994) and Lee and Schmidt (1996).
} 
(AIC; Akaike, 1973) and the Bayesian information criterion (BIC; Akaike, 1979) were used to select the appropriate AR and MA orders in the models. ${ }^{5}$

Table 3 displays the fractional parameter $\mathrm{d}$ and the AR and MA terms obtained using Sowell's (1992) maximum likelihood estimator of various ARFIMA (p, d, q) specifications with all combinations of $\mathrm{p}, \mathrm{q} \leq 2$, for each time series.

Table 3. Results of long memory tests

Long memory test

\begin{tabular}{|c|c|c|c|c|c|c|}
\hline Data analyzed & $\begin{array}{l}\text { Sample size } \\
\text { (weeks) }\end{array}$ & Model Selected & d & Std. Error & Interval & $\mathrm{I}(\mathrm{d})$ \\
\hline OPEC oil prices & 444 & $\operatorname{ARFIMA}(2, \mathrm{~d}, 2)$ & 0.8638194 & 0.1186592 & {$[0.67,1.06]$} & $\mathrm{I}(1)$ \\
\hline OPEC oil production & 588 & $\operatorname{ARFIMA~}(2, \mathrm{~d}, 2)$ & 0.8699298 & 0.0456837 & {$[0.79,0.95]$} & $\mathrm{I}(\mathrm{d})$ \\
\hline
\end{tabular}

We observe from Table 3 that the estimates of $d$ in OPEC oil prices are equal I(1) and $\mathrm{I}(\mathrm{d})$ for OPEC oil production time series. In both cases, the values of $d$ are in the range $(0,1)$, implying fractional integration. Also, the value of $d$ in both time series are below 1. With this result, we could conclude that these two time series are mean reverting, implying transitory shocks and thus, in the event of an exogenous shock the series will return to its original trend in the future. But if we look at the confidence intervals, we cannot reject the hypothesis of I(1) for the OPEC oil prices.

\subsection{FCVAR model $(d \neq b)$}

\footnotetext{
${ }^{5}$ A point of caution should be adopted here since the AIC and BIC may not necessarily be the best criteria for applications involving fractional models (Hosking, 1981).
} 
Next, the FCVAR model proposed by Johansen and Nielsen (2012), where the fractional integration and the classical CVAR model join is used in order to contrast the possible existence of persistence in the long run co-movements of the series. Table 4 summarizes the results of the FCVAR model.

Table 4. Results of FCVAR model

\begin{tabular}{lcc}
\hline & d & b \\
\hline \hline Panel I: OPEC oil prices and & $d=0.800$ & $b=0.800$ \\
Terrorism attacks & $(0.136)$ & $(0.000)$ \\
& & \\
Panel II: OPEC oil production and & $d=0.857$ & $b=0.857$ \\
Terrorism attacks & $(0.061)$ & $(0.000)$ \\
& & \\
\hline
\end{tabular}

We follow the indications suggested by Jones, Nielsen and Popiel (2014) about the lag value $(\mathrm{k}=3)$. Also, we consider deterministic components and cointegration rank $(r)$ to get our results. We observe from Panel I and Panel II (cointegrating the OPEC oil prices and OPEC oil production with terrorism attacks) in Table 4 that the order of integration of the individual series are about 0.800 and 0.857 , respectively while the reduction in the degree of integration in the cointegrating regression is exactly of the same magnitude, implying that the order of integration $(d-b)=0$, which in turn implies $\mathrm{I}(0)$ cointegration errors. Thus, we cannot reject the hypothesis in which the error correction term shows short-run stationary behavior and where the shock duration is short-lived. These results are in line with those obtained using fractional integration.

\subsection{Structural breaks and Continuous Wavelet Transform}


In order to verify if the terrorism has caused any change in oil prices and oil production in OPEC countries, we use Perron and Vogelsan (1992) and Bai and Perron (2003) approaches for detecting breaks in the data. The break dates, for the monthly case are reported in Table 5.

Table 5. Structural breaks

Time Series

Number of breaks chosen by BIC

\section{Structural break dates}

\begin{tabular}{lcc}
\hline \hline & & February 2002 \\
OPEC Oil Prices & 3 & September 2007 \\
& & May 2013 \\
& & April 1981 \\
OPEC Oil Production & 5 & August 1988 \\
& 5 & December 1995 \\
& & April 2004 \\
Terrorism & 2 & April 2004 \\
& & January 2014 \\
\hline
\end{tabular}

Following the BIC criterion to choose the number of structural breaks, we see that the most relevant ones in the terrorism time series are two, which are close to those found in the unit roots tests previously analyzed.

Figure 2 displays the wavelet coherency and the phase difference for the monthly data of terrorist attacks and OPEC oil production and OPEC oil prices showing evidence of varying dependence between the time series across different frequencies and over time. Also, with this methodology we can see when a structural change occurs in the behavior of crude oil prices and crude oil production with respect to terrorist attacks.

Figure 2: Wavelet coherency and phase difference between terrorist attacks in the OPEC oil production and oil prices. 


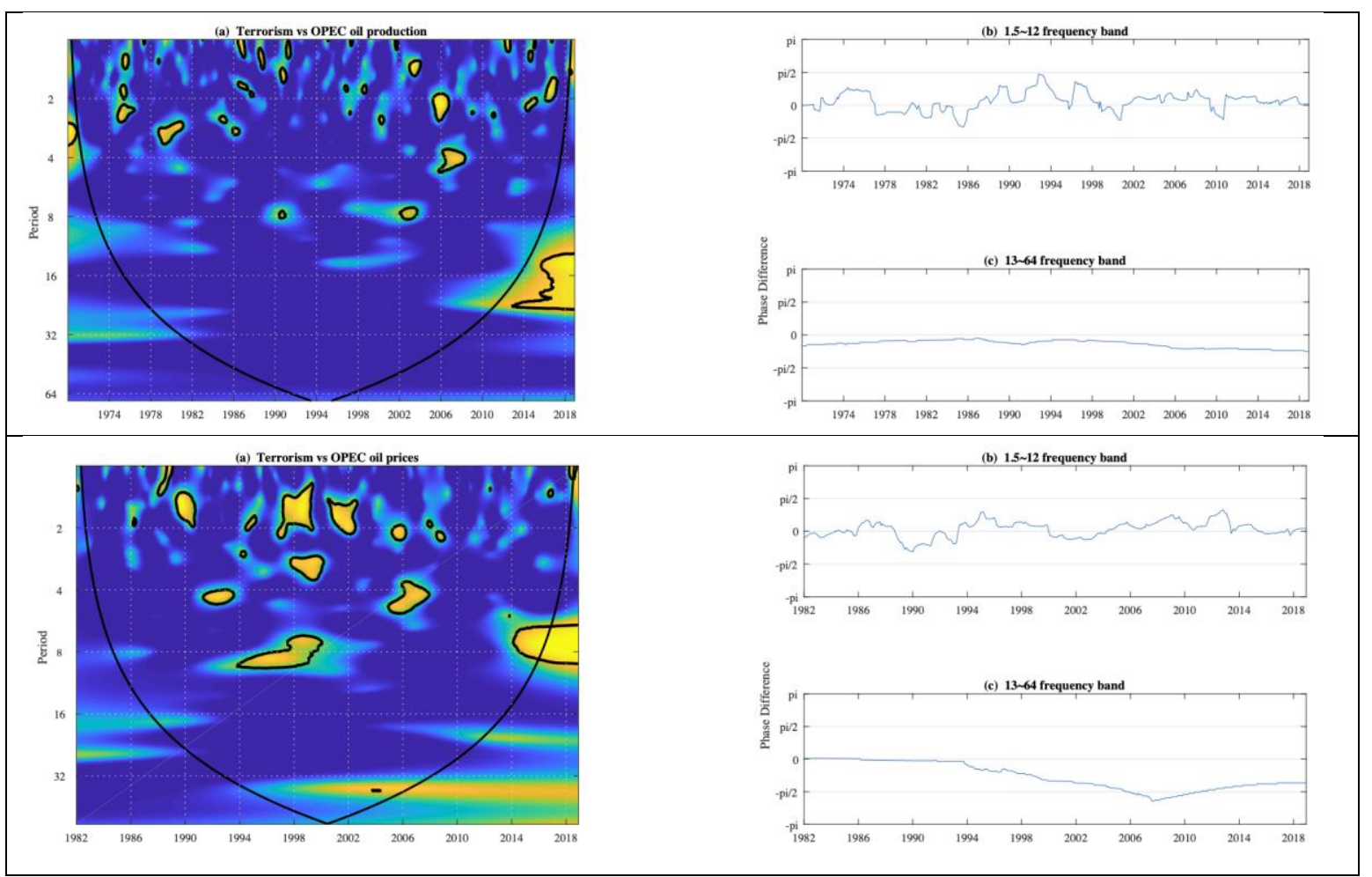

The contour designates the 5\% significance level. Coherency ranges from blue (low coherency) to yellow (high coherency). (a) Wavelet coherency. ( $b$ )-(c) Phase difference.

Figure 2 represents two different estimations. The left panel (a) has the wavelet coherency that represents the interrelations between OPEC oil production and OPEC oil prices with respect to terrorism, when they are stronger or not and at which frequencies these points occur. Frequencies are shown on the vertical axis, from scale 1 (a single month) up to scale 64 (approximately 5 years), whereas time is shown in the horizontal axis, from the beginning to the end of the sample period. The statistical significance of local correlations in the time-frequency domain was evaluated using Monte Carlo simulations. The regions surrounded by the black contour are the high frequency and the high coherence regions with significance values at 5\%, that are the outcome obtained. The right panel has the phase differences: at the top (b) is the phase difference in the 1.5-12 frequency band for monthly data; at the bottom (c) is the phase difference in the 13-64 frequency band for monthly data. The frequency bands helps us to understand the movement of both time series, one in relation to the other. 
Also, we consider the structural breaks found in the terrorist attacks time series (2004:04 and 2014:01), using Bai and Perron (2003), to analyze the relationship between OPEC oil prices and OPEC oil production and terrorism using wavelet analysis.

The main regions with statistically significant coherency are in low frequencies (corresponding to cycles between 1 to 12 months) in both cases, for production and prices.

A more accurate result is that, in the case of terrorism and OPEC oil production we find a region in the coherency figure corresponding to the first structural break (2004:04) in the short-term frequencies, between 3 and 6 months. In the case of Terrorism and OPEC oil prices, we can conclude that the two structural breaks that we found previously (2004:04; 2014:01) are represented in the figure of coherency, in the low frequency corresponding to cycles between 3 and 6 months and 7 and 12 months, respectively. These results are in line with the results that we get in the previous sections, where we state that the impact of the terrorist attacks in the oil production and oil prices has a short-term component.

The second estimation is the partial phase-difference (represented in the right part of the Figure 2) that gives us information about the movement of one time series with respect to the other. Focusing on the regions mentioned above, with high coherency at the 5\% significance level, we can appreciate that all these regions stay between 0 and $\pi / 2$ which means that terrorist attacks are positively correlated and leading in the behavior of oil production and oil prices in OPEC.

Once we have identified the structural changes that have occurred due to the terrorist attacks, and we have concluded that the terrorist attacks affected production in OPEC countries in May 2004 and prices in OPEC countries in May 2004 and January 2014, we statistically analyze the behavior of these series after each shock. To do so, we apply 
ARFIMA models. The results are reported in Table 6.

Table 6. Results of long memory tests before and after structural breaks

Long memory test

\begin{tabular}{|c|c|c|c|c|c|c|}
\hline Data analyzed & $\begin{array}{l}\text { Sample size } \\
\quad \text { (weeks) }\end{array}$ & Model Selected & d & Std. Error & Interval & $\mathrm{I}(\mathrm{d})$ \\
\hline \multicolumn{7}{|c|}{ OPEC oil prices } \\
\hline $\begin{array}{l}\text { OPEC oil prices - } \\
\text { after break } 2004\end{array}$ & 118 & $\operatorname{ARFIMA}(2, \mathrm{~d}, 1)$ & 0.4072463 & 0.1950897 & {$[0.09,0.73]$} & $\mathrm{I}(\mathrm{d})$ \\
\hline $\begin{array}{l}\text { OPEC oil prices - } \\
\text { before break } 2014\end{array}$ & 118 & $\operatorname{ARFIMA}(2, \mathrm{~d}, 1)$ & 0.4072463 & 0.1950897 & {$[0.09,0.73]$} & $\mathrm{I}(\mathrm{d})$ \\
\hline $\begin{array}{l}\text { OPEC oil prices - } \\
\text { after break } 2014\end{array}$ & 60 & $\operatorname{ARFIMA}(2, \mathrm{~d}, 2)$ & 0.296182 & 0.474025 & {$[-0.48,1.08]$} & $\mathrm{I}(0), \mathrm{I}(1)$ \\
\hline \multicolumn{7}{|c|}{ OPEC oil production } \\
\hline $\begin{array}{l}\text { OPEC oil production } \\
\text { - after break } 2004\end{array}$ & 118 & $\operatorname{ARFIMA}(2, \mathrm{~d}, 2)$ & 0.802797 & 0.156333 & {$[0.55,1.06]$} & $\mathrm{I}(1)$ \\
\hline
\end{tabular}

We observe from Table 6 that the estimates of $d$ after structural changes in oil prices and oil production in OPEC are in the range $(0,1)$, implying fractional integration in both time series, oil prices and oil production, respectively.

Focusing on the behavior of the time series after the first break (2004:04), we conclude that $\mathrm{d}=0.40$ for oil prices, implying that the shock was transitory recovering its original trend in the short term. On the other hand, $\mathrm{d}=0.80$ for oil production, but although apparently the result is similar to oil prices mentioned before, we cannot reject the hypothesis of I (1).

Finally, focusing on the behavior of the OPEC oil prices after the second break (2014:01), we observe that $d=0.29$. The value of $d$ is below 1 . With this result, we could conclude 
that after the structural break the time series is mean reverting, also implying transitory shocks. But if we look at the confidence interval, we cannot reject the hypothesis of I(1).

\section{Conclusions}

This paper contributes to the literature on understanding the behavior of the OPEC oil prices and OPEC oil production in response to terrorist attacks in these countries. To this purpose, we analyze the statistical properties of these time series, measuring the degree of persistence by using fractional integration techniques. Moreover, we analyze the long-term relationship of the time series using the Fractional Cointegration VAR (FCVAR) approach. Finally, we examine the possible structural changes in oil prices and oil production caused by the terrorist attacks in OPEC countries using methodologies based on Bai and Perron (2003) and wavelet transform.

In this research we have analyzed the number of terrorist events per month from the Global Terrorism Database (National Consortium for the Study of Terrorism and Responses to Terrorism (START), 2020) and its effects on crude oil production and crude oil prices behavior, from January 1970 to December 2018.

Given that OPEC is a dominant supplier in the oil market, assuming that OPEC has a superior understanding of the dynamics of the market and the ability to restrict supplies (Hansen and Lindholt 2008) and noting the terrorism and war events which have taken place in the main oil producing countries over the last 30 years, we analyze these three time series to gain a better understanding of the consequences of terrorist events on OPEC's crude oil production and OPEC's crude oil prices, examining the statistical properties of the time series using fractional integration techniques to measure the degree of persistence and analyzing the long-term relationships of the time series using the Fractional Cointegration VAR model (FCVAR). We also study the dynamics in the time- 
frequency domain applying wavelet tools for its resolution.

We started by performing several unit root methods, including ADF (Dickey and Fuller, 1979), PP (Phillips and Perron, 1988), and KPSS (Kwiatkowski et al., 1992). The results suggest that the time series are nonstationary $\mathrm{I}(1)$. In addition, we use two unit root tests with structural breaks onto the time series based on Narayan and Popp (2010) ADF-type unit root test and the LM test, proposed by Lee and Strazicich (2003). Taking into account that the analyzed time series could have structural changes, we carried out the analysis of unit roots with structural changes and the results indicate that the time series follow a stationary behavior.

As we have explained throughout this research paper, time series depend not only on a finite number of past observations but on the whole of its past history. In this context, techniques based on fractional integration play a crucial role since it indicates the degree of dependence of the series and allow us to know if the impact of terrorism on the OPEC oil prices and OPEC oil production is temporary or permanent. The results that we get using the ARFIMA model indicate that the values of $d$ are in the range $(0$, 1), implying fractional integration. These values are below 1, implying mean reversion and thus, in the event of an exogenous shock the series will return to its original trend in the future.

In the multivariate case by using a FCVAR model and where we study the relationship of OPEC's crude oil production and OPEC's crude oil prices with terrorism attacks, we observe that the results are in line with the previous one where the order of integration of the individual series are below 1 ( 0.800 and 0.857 , respectively) while the reduction in the degree of integration in the cointegrating regression is exactly of the same magnitude, implying that the order of integration $(d-b)=0$. This implies $\mathrm{I}(0)$ cointegration errors. Thus, we cannot reject the hypothesis in which the error correction 
term shows short-run stationary behavior and where the shock duration is short-lived.

Following the results obtained and taking into account the structural changes caused by the terrorist attacks found by the unit roots tests of Narayan and Popp (2010) and Lee and Strazicich (2003), and in order to be more precise in our calculations we use Perron and Vogelsan (1992) and Bai and Perron (2003) approaches for detecting breaks in the data. The most relevant structural changes that have occurred in the time series of terrorist attacks have been in 2004: 04 and 2014: 01.

In order to know how terrorist attacks and OPEC oil prices and OPEC oil production are related at different frequencies and how such relationships have evolved over time, we use Continuous Wavelet Transform. We observe that terrorist attacks had an influence on oil prices in the periods 2004: 04 and 2014: 01. However, in oil production, we only find a clear influence in the period 2004: 04. Using this methodology, we state that terrorist attacks have a short-term component and they are positively correlated and leading in the behavior of oil production and oil prices in OPEC. The shocks found took between 1 and 10 months to disappear.

Finally, once we have identified the structural changes that have occurred due to the terrorist attacks, and we have concluded that the terrorist attacks affected production in OPEC countries in May 2004 and prices in OPEC countries in May 2004 and January 2014, we statistically analyze the behavior of these series after each shock, concluding that after the structural break the time series are mean reverting, implying transitory shocks.

This paper can be very helpful to institutions and companies that are exposed to crude oil market changes. Our findings might help market participants to understand better what the impact of terrorism on crude oil production movements may be and its subsequent potential effects on hedging strategies. It would be also reasonable to extend 
this research to other influence groups in the oil industry or high producing countries such as the U.S. or Russia, especially when the development of new production techniques such as fracking have been gaining relevance in the last years, increasing worldwide resources and shifting the balance of power and influence between countries.

Finally, we believe that it would be very interesting to incorporate variables that try to capture the effect of COVID-19, since there are already some studies that confirm that it could have important structural consequences for the oil industry. In future research, we will try to analyze and incorporate these variables, as we believe that they may be a determining factor in the future to define the effect of terrorism on oil production and prices in OPEC. 


\section{References}

Adams, N. (2003). Terrorism and Oil, PennWell Publishers, Tulsa, OK.

Aguiar-Conraria, L., Azevedo, N. and Soares, M. J. (2008). Using wavelets to decompose the time-frequency effects of monetary policy. Physica A: Statistical Mechanics and its Applications, 387, 2863-2878.

Aguiar-Conraria, L. and Soares, M. J. (2011). Oil and the macroeconomy: using wavelets to analyze old issues. Empirical Economics, 40, 645-655.

Aguiar-Conraria, L. and Soares, M. J. (2014). The continuous wavelet transform: moving beyond uni- and bivariate analysis. Journal of Economic Survey, 28, 344-375.

Akaike, H. (1973). Maximum likelihood identification of Gaussian autoregressive moving average models. Biometrika, 60(2), 255-265.

Akaike, H. (1979). A Bayesian extension of the minimum AIC procedure of autoregressive model fitting. Biometrika, 66(2), 237-242.

Aon. (2020). <https://www.aon.com/2020-political-risk-terrorism-and-politicalviolence-maps/index.html?utm_source=aoncom\&utm_medium=2017-prm-

redirect\&utm_campaign=riskmaps2018>

Arora, V. and Tanner, M. (2013). Do oil prices respond to real interest rates? Energy Economics, 36, 546-555.

Aslaksen, S. (2010). Oil and democracy: More than a cross-country correlation?. Journal of Peace Research, 47(4), 421-431.

Adenstedt, R.K. (1974) On Large-Sample Estimation for the Mean of a Stationary Random Sequence, The Annals of Statistics 2, 6, 1095-1107.

Aye, G. C., Carcel, H., Gil-Alana, L. A. and Gupta, R. (2017). Does gold act as a hedge against inflation in the UK? Evidence from a fractional cointegration approach over 1257 to 2016. Resources Policy, 54, 53-57.

Bakas, D. and Triantafyllou, A. (2020). Commodity Price Volatility and the Economic Uncertainty of Pandemics. SSRN Electronic Journal. https://doi.org/1 $\underline{0.2139 / \mathrm{ssrn} .3581193}$

Bahgat, G. (2004). Terrorism and Energy: Potential for a Strategic Realignment. World Affairs, 167(2), 51-58.

Bagchi, B. (2017). Volatility spillovers between crude oil price and stock markets: evidence from BRIC countries. International Journal of Emerging Markets, 12 (2), 352365 .

Bai, J. and P. Perron (2003). Computation and analysis of multiple structural change models. Journal of Applied Econometrics 18, 1-22. 
Barros, C. P., Gil-Alana, L. A. and Payne, J. E. (2011). An analysis of oil production by OPEC countries: Persistence, breaks, and outliers. Energy Policy, 39, 442-453.

Bassil, C., Hamadi, H. and Bteich, M. (2018). Terrorism in OPEC countries and oil prices. International Journal of Emerging Markets. 13. 00-00. 10.1108/IJoEM-11-20170493.

Baumeister, C. and Kilian, L. (2012). Real-time forecasts of the real price of oil. Journal of Business and Economic Statistics, 30, 326-336.

Baumeister, C. and Peersman, G. (2013), The role of time-varying price elasticities in accounting for volatility changes in the crude oil market. Journal of Applied Econometrics, 28 (7), 1087-1109.

Baumeister, C. and Kilian, L. (2014). What central bankers need to know about forecasting oil prices. International Economic Review, 55, 869-889.

Baruník, J. and Dvořáková, S. (2015). An empirical model of fractionally cointegrated daily high and low stock market prices. Economic Modelling, 45, 193-206.

Beckmann, J. and Czudaj, R. (2013). Is there a homogeneous causality pattern between oil prices and currencies of oil importers and exporters? Energy Economics, 40, 665-678.

Blomberg, B., Hess, G. and Jackson, J.H. (2009). Terrorism and the returns to oil. Economics and Politics, 21 (3), 409-432.

Chen, H., Liao, H., Tang, B-J. and Wei, Y.M. (2016). Impacts of OPEC's political risk on the international crude oil prices: An empirical analysis based on the SVAR models. Energy Economics, 57, 42-49.

Coleman, L. (2012). Explaining crude oil prices using fundamental measures. Energy Policy, 40, 318-324.

Colgan, J. D. (2013). Fueling the Fire: Pathways from Oil to War. International Security, 38, 147- 180.

Collier, P. and Hoeffler, A. (1998). On economic causes of civil war. Oxford Economic Papers, 50, 563-573.

Cook, D. (2008). The global energy market: comprenhensive strategies to meet geopolitical and financial risks. Institute for public policy (Rice University). <https://www.bakerinstitute.org/media/files/Research/b5edc3ae/IEEJoilterrorismCook.pdf\&gt; >.

Cooper, J. (2003). Price elasticity of demand for crude oil: estimates for 23 countries, OPEC Energy Review, 27(1), 1-8.

Dewandaru, G., Masih, R. and Masih, A. M. M. (2016). Contagion and interdependence across Asia-Pacific equity markets: An analysis based on multi-horizon discrete and 
continuous wavelet transformations. International Review of Economics and Finance, 43, 363-377.

Dickey, D. A., and Fuller, W. A. (1979). Distribution of the estimators for autoregressive time series with a unit root. Journal of the American Statistical Association, 74(366a), 427-431.

Diebold, F.X. and Rudebush, G. D. (1991). On the power of Dickey-Fuller tests against fractional alternatives. Economics Letters, 35, 155-160.

Dittmann, I., and Granger, C. W. J., (2002). Properties of nonlinear transformations of fractionally integrated processes. Journal of Econometrics, 110, 113-133.

Dolatabadi, S., Narayan, P. K., Nielsen and M. Ø., Xu, K. (2018). Economic significance of commodity return forecasts from the fractionally cointegrated VAR model. Journal of Futures Markets, 38(2), 219-242.

EIA, Annual Energy Outlook. Energy Information Administration (EIA) (2019).

Elliot, G., T.J. Rothenberg and J.H. Stock (1996), Efficient tests for an autoregressive unit root, Econometrica 64, 813-836.

Fattouh, B. (2007). How secure are Middle East oil supplies? Oxford Institute for Energy Studies.

Fearon, J. D. (2005). Primary Commodity Exports and Civil War. Journal of Conflict Resolution, 49, 483-507.

Fuller, W. A. (1976). Introduction to Statistical Time Series, New York: JohnWiley. Fuller Introduction to Statistical Time Series.

Geweke, J. and Porter-Hudak, S. (1983). The estimation and application of long memory time series models. Journal of Time Series Analysis, 4 (4), 221-238.

Gil-Alana, L. A. and Carcel, H. (2020). A fractional cointegration var analysis of exchange rate dynamics. The North American Journal of Economics and Finance, 51, 100848 .

Gil-Alana, L. A. and Monge, M. (2020). Crude Oil Prices and COVID-19: Persistence of the Shock. Energy Research Letters, 1(1).

Granger, C.W.J. and R. Joyeux (1980) An introduction to long-memory time series models and fractional differencing, Journal of Time Series Analysis 1, 15-29.

Granger, C.W.J. (1980) Long memory relationships and the aggregation of dynamic models, Journal of Econometrics 14:2, 227-238.

Granger, C.W.J. (1981) Some properties of Time Series data and their use in Econometric Model Specification, Journal of Econometrics 16, 121-131. 
Hansen, P.V. and Lindholt, L. (2008). The market power of OPEC 1973-2001. Applied Economics, 40, 2939-2959.

Hamilton, J.D. (2009). Causes and consequences of the oil shock of 2007-08. Brookings Papers on Economic Activity, Spring, 2009, 215-261.

Hassler, U., and Wolters, J. (1994). On the power of unit root tests against fractional alternatives. Economics Letters, 45(1), 1-5.

Hendrix, C. S. (2017). Oil Prices and Interstate Conflict Behavior. Conflict Management and Peace Science, 34(6), 575-596.

Hoffman, B. (2006). Inside Terrorism. Political Science Quarterly, 114, 432.

Hosking, J.R.M. (1981), Modelling persistence in hydrological time series with using fractional differentiation, Water Resources Research 20, 1898-1908.

Huang, S., An, H., Wen, S. and An, F. (2017). Revisiting driving factors of oil price shocks across time scales. Energy, 139, 617-629.

Humphreys, M. (2005). Natural Resources, Conflict, and Conflict Resolution: Uncovering the Mechanisms. Journal of Conflict Resolution, 49, 508-537.

International Energy Agency 2019. Key World Energy Statistics 2019 OECD/iea 2019.

Jammazi, R., Ferrer, R., Jareño, F., and Shahzad, S. J. H. (2017). Time-varying causality between crude oil and stock markets: What can we learn from a multiscale perspective?. International Review of Economics and Finance, 49, 453-483.

Javid, A. Y. and Ahmad, B. (2020). Event Study and Impulse Indicator Saturation Analysis to Assess Reaction of Terrorist and Political Events: Evidence from Oil and Gas Sector of Pakistan. Journal of Quantitative Methods, 4(1), 77-98.

Jensen, N. and Wantchekon, L. (2004). Resource Wealth and Political Regimes in Africa. Comparative Political Studies, 37, 816-841.

Johansen, S. (1996). Likelihood-based inference in cointegrated vector autoregressive models. New York, NY: Oxford University Press.

Johansen, S. (2008). A representation theory for a class of vector autoregressive models for fractional processes. Econometric Theory, 24, 651-676.

Johansen, S., Nielsen, M. Ø. (2010). Likelihood inference for a nonstationary fractional autoregressive model. Journal of Econometrics, 158, 51-66.

Johansen, S. and Nielsen, M. Ø. (2012). Likelihood inference for a fractionally cointegrated vector autoregressive model. Econometrica, 80, 2667-2732.

Johansen, S. and M. Ø. Nielsen (2014). The role of initial values in nonstationary fractional time series models. QED working paper 1300, Queen's University. 
Jones, M. E., Nielsen, M. Ø. and Popiel, M. K. (2014) A fractionally cointegrated VAR analysis of economic voting and political support. Canadian Journal of Economics, 47, 1078-1130.

Jun, X. (2017). Do futures prices help forecast the spot price? Journal of Futures Markets, $37,1205-1225$.

Kingsly, K., and Henri, K. (2020). COVID-19 and Oil Prices. Development Economics: Agriculture.

Kollias, C., Kyrtsou, C. and Papadamou, S. (2013). The effects of terrorism and war on the oil price- stock index relationship. Energy Economics, 40, 743-752.

Kwiatkowski, D., Phillips, P. C., Schmidt, P. and Shin, Y. (1992). Testing the null hypothesis of stationarity against the alternative of a unit root. Journal of Econometrics, 54(1-3), 159-178.

Lambrechts, D. And Blomquist, L. B. (2017). Political-security risk in the oil and gas industry: the impact of terrorism on risk management and mitigation. Journal of Risk Research, 20 (10), 1320-1337.

Lee, D., and Schmidt, P. (1996). On the power of the KPSS test of stationarity against fractionally-integrated alternatives. Journal of Econometrics, 73(1), 285-302.

Lee, C. (2016). Oil and Terrorism: Uncovering the Mechanisms. Journal of Conflict Resolution 62, 903-928.

Lee, J., and Strazicich, M. C. (2003). Minimum Lagrange multiplier unit root test with two structural breaks. Review of economics and statistics, 85(4), 1082-1089.

Lee, C. C., Lee, C. C. and Ning, S. L. (2017). Dynamic relationship of oil price shocks and country risks. Energy Economics, 66, 571-581.

Luft, G. and Korin, A. (2004), Terrorism Goes to Sea. <www.foreignaffairs.com/articles/oceans/2004-11-01/terrorism-goes-sea>

Maciel, L. (2017). Technical analysis based on high and low stock prices forecasts: Evidence for Brazil using a fractionally cointegrated VAR model. Empirical Economics, V58(4), 1513-1540.

Miao, H., Ramchander, S., Wang, T. and Yang, D. (2017). Influential factors in crude oil price forecasting. Energy Economics, 68, 77-88.

Monge, M., Gil-Alana, L. A. and de Gracia, F. P. (2017a). Crude oil price behaviour before and after military conflicts and geopolitical events. Energy, 120, 79-91.

Monge, M., Gil-Alana, L. A., and de Gracia, F. P. (2017b). US shale oil production and WTI prices behavior. Energy, 141, 12-19. 
Monge, M. and Gil-Alana, L. A. (2020). Water prices: persistence, mean reversion and trends. Water policy 22, 1200-1216.

Monge, M., and Gil-Alana, L. A. (2021). Spatial crude oil production divergence and crude oil price behaviour in the United States. Energy, 121034.

Morrison, K. M. (2009). Oil, Nontax Revenue, and the Redistributional Foundations of Regime Stability. International Organization, 63, 107.

Murat, A., and Tokat, E. (2009). Forecasting oil price movements with crack spread futures. Energy Economics, 31, 85-90.

Narayan, P.K. (2019). Can stale oil price news predict stock returns? Energy Economics, $83,430-444$.

Narayan, P. K. (2020). Oil price news and COVID-19-Is there any connection? Energy Research Letters, 1(1). <https://doi.org/10.46557/001c.13176>

Narayan, P. K., and Popp, S. (2010). A new unit root test with two structural breaks in level and slope at unknown time. Journal of Applied Statistics, 37(9), 1425-1438.

Narayan, P. K., \& Popp, S. (2013). Size and power properties of structural break unit root tests. Applied Economics, 45(6), 721-728.

Nelson, C.R. and C.I. Plosser (1982) Trends and random walks in macroeconomic time series: Some evidence and implications, Journal of Monetary Economics10:2, 139-162.

$\mathrm{Ng}$, S. and P. Perron (2001), Lag length selection and the construction of unit root tests with good size and power, Econometrica 69, 519-1554

Nielsen, M.Ø. and L. Morin (2014) FCVAR model: a Matlab software package for estimation and testing in the fractionally cointegrated VAR model, QED Working Paper 1273, Queens University.

Nielsen, M. Ø. and Popiel, M. K. (2018). A Matlab program and user's guide for the fractionally cointegrated VAR model (Queen's Economics Department Working Paper No 1330). Ontario, Canada, K7L 3N6.

Orbaneja, J.R.V., Iyer, S.R. and Simkins, B.J. (2018). Terrorism and oil markets: A crosssectional evaluation. Finance Research Letters 24, 42-48.

Perron, P. and T.J. Vogelsang (1992). Testing for a Unit Root in a Time Series with a Changing Mean: Corrections and Extensions, Journal of Business and Economic Statistics 10, 4, 467-470.

Phan, D., Narayan, P. and Gong, Q. (2021). Terrorist attacks and oil prices: Hypothesis and empirical evidence. International Review of Financial Analysis, 74.

Phillips, P. C. (1987). Time series regression with a unit root. Econometrica, 55(2), 277301. 
Phillips, P. C., and Perron, P. (1988). Testing for a unit root in time series regression. Biometrika, 75(2), 335-346.

Phillips, P. C. B. (1999). Discrete Fourier transforms of fractional processes. Department of Economics, University of Auckland.

Phillips, P. C. B. (2007). Unit root log periodogram regression. Journal of Econometrics, 138(1), 104-124.

Poza, C., and Monge, M. (2020). A real time leading economic indicator based on text mining for the Spanish economy. Fractional cointegration VAR and Continuous Wavelet Transform analysis. International Economics, 163, 163-175.

Ramsay, K. W. (2011). Revisiting the resource curse: natural disasters, the price of oil, and democracy. International Organization, 65(3), 507-529.

Richman, V., Santos, M.R. and Barkoulas, J.T. (2011). Short and long term effects of the 9/11 event. The international evidence. International Journal of Theoretical and Appliaed Finance, 8, 947-958.

Robinson, P.M. (1994) Efficient tests of nonstationary hypotheses, Journal of the American Statistical Association 89, 1420-1437.

Robinson, P.M. (1995a) Gaussian semi-parametric estimation of long range dependence, Annals of Statistics 23, 1630-1661.

Robinson, P.M. (1995b), Log periodogram regression of time series with long range dependence, Annals of Statistics 23, 3, 1048-1072.

Ross, M. L. (2001). Does Oil Hinder Democracy? World Politics, 53, 325-361.

Ross, M. L. (2004a). How Do Natural Resources Influence Civil War? Evidence from Thirteen Cases. International Organization, 58, 35-67.

Ross, M. L. (2004b). What Do We Know about Natural Resources and Civil War? Journal of Peace Research, 41, 337-356.

Salisu, A. A., Ebuh, G. U. and Usman, N. (2020). Revisiting oil-stock nexus during COVID-19 pandemic: Some preliminary results. International Review of Economics and Finance, 69, 280-294.

Şen, Ş. and Babal1, T. (2007). Security concerns in the Middle East for oil supply: Problems and solutions. Energy Policy, 35, 1517-1524.

Sowell, F. (1992). Maximum likelihood estimation of stationary univariate fractionally integrated time series models. Journal of Econometrics, 53(1-3), 165-188.

Tahir Suleman, M. (2012). Stock market reaction to terrorist attacks: Empirical evidence from a front line state. Australasian Accounting, Business and Finance Journal, 6(1), 97110. 
Tichý, L. (2019). The Islamic State oil and gas strategy in North Africa. Energy Strategy Reviews, 24, 254-260.

Tiwari, A. K., Mutascu, M. I. and Albulescu, C. T. (2016). Continuous wavelet transform and rolling correlation of European stock markets. International Review of Economics and Finance, 42, 237-256.

Toft, P. (2011). Intrastate conflict in oil producing states: A threat to global oil supply? Energy Policy, 39, 7265-7274.

Vacha, L. and Barunik, J. (2012). Co-movement of energy commodities revisited: Evidence from wavelet coherence analysis. Energy Economics, 34, 241-247.

Zhang, Y. and Wei, Y. (2011). The dynamic influence of advanced stock market risk on international crude oil returns: An empirical analysis. Quantitative Finance, 11, 967-978. 